\title{
NegotioPoly: a holistic gaming approach to negotiation teaching
}

\author{
Tuvana Rua
}

Department of Management, Quinnipiac University, Hamden, Connecticut, USA

Zeynep Aytug

Department of Management, California State Polytechnic University Pomona, Pomona, California, USA, and

Leanna Lawter

Department of Economics, Wheaton College, Norton, Massachusetts, USA

\begin{abstract}
Purpose - Based on Behavioral Theory of Negotiations (Walton \& McKersie, 1965), the purpose of this paper is to discuss the existing gap between negotiation theory and pedagogy and presents an experiential teaching tool that closes this gap. The tool is a 'serious game' (Abt, 1975) that reinforces all four core negotiation subprocesses while allowing students to practice their negotiation skills and several critical business competencies in a realistic and improvisational context.

Design/methodology/approach - After successfully using NegotioPoly for five years, qualitative and quantitative data were collected in three sections of negotiation classes to assess student learning and behaviors while playing NegotioPoly and to collect student feedback on the effectiveness of NegotioPoly in teaching and reinforcing key negotiation skills.

Findings - Findings support that NegotioPoly is highly effective in engaging students in a series of realistic negotiations, joint problem solving and strategic decision-making. Results show that, during the game, students demonstrate their negotiation skills and learnings, and they practice all four negotiation subprocesses of distributive, integrative and intraorganizational bargaining and attitudinal structuring.

Practical implications - NegotioPoly enables students to engage in distributive and integrative bargaining, multiple levels of negotiations and coalitions in quick succession. Students practice organizational politics and adjust their negotiations based on relationships and social realities, as they demonstrate advanced deal-making behaviors and core business competencies of problem solving, decision-making, analytical skills and ability to work with others.

Social implications - NegotioPoly reinforces core business competencies such as negotiation, problem solving, analytical skills and the ability to work in teams that employers look for and, therefore, is a useful tool for preparing students for the business world.

Originality/value - NegotioPoly is an experiential learning tool that closes the gap between negotiation theory and pedagogy while providing deep learning and realistic practice opportunities for students where they can use their negotiation skills in a gaming environment that uses multi-party and multi-round negotiations.
\end{abstract}

Keywords Behavioral theory of negotiations, Negotiation subprocesses, Multi-party negotiation, Multi-round negotiation, Game-based learning

Paper type Technical paper

(C) Tuvana Rua, Zeynep Aytug and Leanna Lawter. Published in Organization Management Journal. Published by Emerald Publishing Limited. This article is published under the Creative Commons Attribution (CC BY 4.0) licence. Anyone may reproduce, distribute, translate and create derivative works of this article (for both commercial and non-commercial purposes), subject to full attribution to the original publication and authors. The full terms of this licence maybe seen at http:// creativecommons.org/licences/by/4.0/legalcode 
OMJ

19,4

\section{Introduction}

Managers rely on their negotiation skills as they resolve conflicts and secure agreements with inter- and intra-organizational partners. As a result, negotiation courses are highly demanded in business schools (Malhotra \& Bazerman, 2008; Thompson \& Leonardelli, 2004). Negotiation classes typically rely on role-playing exercises, which are highly structured and narrowly focused on teaching a specific negotiation skill or reinforcing a specific negotiation theory (Druckman \& Ebner, 2013; Lewicki, 1997). The major pedagogical shortcoming of these simulations is that they do not provide students an environment to practice more unstructured multi-player, multi-round negotiations in an improvisational setting (Alexander \& LeBaron, 2009; Randel, Morris, Wetzel \& Whitehall., 1992; Stokoe, 2011). Consequently, students lack experience in two of the four negotiation sub-processes, i.e. attitudinal structuring and intra-organizational bargaining (Walton \& McKersie, 1965), that provide the conceptual foundations of our current understanding of negotiations (Greenhalgh \& Lewicki, 2015).

In this paper, we discuss the importance of engaging learners in a simulation that incorporates all four negotiation sub-processes (Walton \& McKersie, 1965) and introduce an original and innovative game to address the current discrepancy between negotiation theory and pedagogy. Using eight unique rules designed for effective experiential teaching, NegotioPoly uses the traditional Monopoly game allowing instructors to cover a wide variety of negotiation concepts and strategies and enables practice of all four negotiation sub-processes, distributive, integrative, attitudinal structuring and intra-organizational bargaining (Walton \& McKersie, 1965), along with several core business competencies. In the next sections, we present Walton and McKersie's Behavioral Theory of Negotiations, explain the theoretical foundation and pedagogical value of the NegotioPoly, introduce the game design and debrief and provide support as to the effectiveness as an experiential learning tool.

\section{Importance of teaching negotiation and core competencies in business education}

Recent research by the National Association of Colleges and Employers (Gray, 2021) shows that the top attributes employers seek in new hires are an ability to work in a team and strong problem-solving, analytical and communication skills. An upper division undergraduate course that combines the development and practice of these core competencies is the negotiation course. Negotiation skills that combine planning, decisionmaking, problem solving, rapport building, teamwork, goal setting and analytical skills (Valdezco, 2021) are critical to communicating effectively with colleagues and business partners, allocating resources, making effective decisions that balance competing interests and resolving problems within and among groups (Malhotra \& Bazerman, 2008). Therefore, it is not surprising that recent employment and labor market research reports show that negotiation skills are increasingly critical for employees who want to advance in management (Peart, 2019). Accordingly, many business schools offer courses on negotiation (Thompson \& Leonardelli, 2004), providing learners with theoretical and conceptual coverage of effective problem solving, decision-making, communication and rapport building in conflict and negotiation contexts.

\section{Theoretical and pedagogical issues with the traditional negotiation exercises}

Engaging in actual negotiations and learning from those experiences is the best method to develop and improve negotiation skills. Consequently, utilization of role-play simulations is the most common teaching method in negotiation courses (André \& Quinquis, 2000; 
Fortgang, 2000; Murnighan, 2002; Rabin, 2010); however, there are certain criticisms of these simulations. The most critical problem is the discrepancy between our theoretical understanding of negotiations and the pedagogical applications of negotiations as the majority of simulations provide coverage of only two of the four major sub-processes of negotiations (Greenhalgh \& Lewicki, 2015).

Walton and McKersie's (1965) book, A Behavioral Theory of Labor Negotiations, is widely accepted to be a seminal work that has provided the theoretical foundation of what developed into today's widespread negotiations pedagogy (Burchill, 1999; CutcherGershenfeld \& Kochan, 2015; Nohria, 2015). Particularly crucial in their theory are the four core negotiation sub-processes that are based on several literatures and theories from a wide variety of fields, including economics, psychology, game theory, group dynamics and industrial relations (Walton \& McKersie, 1965; Kochan \& Lipsky, 2002/2018). These four negotiation subprocesses are distributive bargaining, integrative bargaining, attitudinal structuring and intra-organizational bargaining (Walton \& McKersie, 1965). The first two are well-known among negotiation scholars and instructors. Distributive bargaining subprocess refers to the conflict resolving behaviors in win-lose situations, where the interests of the parties are in opposition and a win-win agreement is not possible (e.g. sales exchanges where the buyer and seller try to move the price in opposite directions). Integrative bargaining refers to the collaborative problem-solving processes used by conflicting parties, who have both opposite and compatible interests. By making strategic tradeoffs, parties can achieve a win-win agreement and maximize their joint benefits (e.g. vendor contract agreements and team decisions regarding budget allocations, where the final agreement should be beneficial for all parties).

Distributive and integrative bargaining are the central bargaining contexts of most classroom simulations, while the third and fourth sub-processes have been mostly absent (Greenhalgh \& Lewicki, 2015). Attitudinal structuring focuses specifically on the relationships between the parties and their perceptions of each other. This subprocess describes the parties' strategic negotiation decisions about how much they can push each other for their own economic advantage without harming the relationship. Given its longterm relationship focus, attitudinal structuring can only be practiced in repeated negotiations between the same parties (Murnighan, 2015). For students to experience and practice attitudinal structuring in a realistic manner, they will have to engage in multi-round negotiations where negotiators focus on not only the economic outcomes of the negotiation but also focus on the subjective outcomes that influence future relationships and negotiations with the other side. Unfortunately, there are very few multi-round negotiation role-play simulations available and even the ones that are available are not used widely because they require multiple class sessions.

The Intra-organizational bargaining model states that individual negotiators do not act independently, but instead represent their organizations or constituents. Intraorganizational bargaining refers to the influence of those constituents on the negotiation, which can require multiple layers of negotiations within an organization prior to negotiating with the other side. For example, before one negotiates a new deal with a supplier, they need to first negotiate with their department members and manager about possible proposals and acceptable terms. These types of exercises are also very limited so practicing intraorganizational bargaining has been mostly absent in many negotiation classes (Greenhalgh \& Lewicki, 2015).

The big four negotiation sub-processes are intricately related, and they cannot be isolated from each other. They engage with each other as we negotiate. For example, without effective practice of attitudinal structuring, distributive strategies may come across 
OMJ 19,4

as selfish or disrespectful, hurting communication and collaboration among the parties. Without effective navigation of intraorganizational bargaining, one cannot fully and effectively prepare proposals or package offers that are acceptable to all involved parties in the organization for an external integrative negotiation. Therefore, in negotiation pedagogy, it is critical to provide both theoretical and experiential coverage of all four sub-processes to develop effective negotiation skills.

There are some additional shortcomings of the commonly used simulations. Role-based simulations have been criticized for:

- falling short in terms of the level of conceptual learning (Randel et al., 1992);

- being limited by learners' level of engagement with the exercises and the level of seriousness while playing the roles (Alexander \& LeBaron, 2009); and

- having a low level of transferability into real life situations (Stokoe, 2011).

These shortcomings have led to calls for modified simulation designs, where learners can be placed in pseudo-reality situations where they personally identify with their roles and engage in the simulated negotiations more realistically and seriously (Ebner \& Efron, 2005). Additionally, it has been recommended to end a semester with a realistic role-play simulation that potentially includes improvisations (Druckman \& Ebner, 2013), to boost role identification, engagement and learning, and to enable the practice and demonstration of all learned negotiation skills. Finally, these improved simulations need to engage learners in all four sub-processes of negotiations to further enhance learning and transferability to real situations (Greenhalgh \& Lewicki, 2015).

\section{Game-based learning for increased motivation, engagement and learning}

In this paper, we focus on game-based learning that refers to the educational use of any type of game, such as board, card or video games (Breuer \& Bente, 2010). Game-based learning enhances learner motivation and boosts concept learning, creating positive learner attitudes and behaviors during learning (Papastergiou, 2009). Therefore, the educational gaming literature offers the concept of serious games (Abt, 1975), where the true intent of the game is to serve an educational purpose rather than having fun as players experience learning as part of the game (Breuer \& Bente, 2010).

Commercial games that are designed for entertainment can later be repurposed by educators to teach or measure certain skills and learning goals. Particularly board games, which are still a favorite among students and in the general population (Jolin, 2016; Taspinar, Schmidt, \& Schuhbauer, 2016), are used to simulate situations where heavy use of communication skills, interaction with others, and strategic thinking are required to solve complex problems for undergraduate and graduate education and corporate training (Bochennek, Wittekindt, Zimmermann, \& Klingebiel, 2007; Breuer \& Bente, 2010; Wong, 2017). Real life negotiations that involve multiple rounds, parties and issues also require heavy use of communication, problem solving, teamwork and analytical skills and are a good fit for using game-based learning tools.

\section{Introducing NegotioPoly: a holistic pedagogical negotiation game}

NegotioPoly is a holistic and versatile educational game that addresses the weaknesses of negotiation role-play simulations. The game uses the Monopoly playboard, making use of some of its mechanics that are familiar to many players; however, NegotioPoly is reengineered as a serious game specifically for negotiation classes. With its eight unique rules (see NegotioPoly Rules), NegotioPoly creates an entirely different process and game 
experience for the players than the traditional Monopoly version that we play with family and friends.

NegotioPoly Rules:

(1) You can buy/sell/trade bus tickets and get out of jail cards.

(2) Any time you end on a property, you have the option to buy it. You can choose to buy the property by yourself or negotiate with another player to buy it together. If you choose not to buy that property, the banker will auction it off to the highest bidding party. During the bidding process, multiple players can negotiate to purchase the property jointly. The individual who landed on the property can also engage in this process (It might be beneficial to purchase the final plot in a color jointly with someone who holds the rest of the properties in that color group, which would require additional negotiations as to the future of all properties and structures - current and future - involved).

(3) You can negotiate the amount of payment or payment terms anytime you land on someone else's property if the property owner is willing.

(4) You can bid on any property you land on even if it is owned by someone else and even if that property already has a structure on it. If the other party is willing to negotiate and you come to an agreement, a transfer of title and structure(s) will take place. You can also negotiate a partnership on the specific property, the structures on it or even other properties and structures in the same color. However, the owner does not have to agree to negotiate or does not have to come to an agreement and sell the property or agree to a partnership even if they agree to negotiate. Alternatively, you can negotiate with the property/structure owner the terms of rent payment.

(5) You can partner with another player to purchase a property and/or structures from the bank or from another player. If two or three players agree to purchase a property and/or structures, these players will have to negotiate the percentage of ownership on the land and/or structures so that they can collect rent or split up proceeds from potential sales accordingly in the future rounds.

(6) You can negotiate a percentage of ownership of structures separately from the land with your partners as you add on more structures to your properties.

(7) You can request a private meeting with the person you are partnering with before you make an offer to another player for his/her property and structures.

(8) At any point in time, you can auction off any of the properties and the existing structures you own to other players and engage in negotiations regarding these properties and/or structures. The other players do not have to bid or negotiate for the property and structures.

NegotioPoly is designed to be used in undergraduate negotiation classes as an end-ofsemester activity. During the game, students engage in a series of multi-party negotiations with different players and on multiple issues. While traditional Monopoly is based on the premise that there will be a sole survivor who forces all others into bankruptcy and monopolizes the game board, NegotioPoly is a joint problem-solving game where players negotiate their way to claim more resources. The competitive element still exists as each negotiation by nature involves a distributive aspect, yet the unique rules promote cooperation to advance each player's goals, leading to integrative negotiations. 
OMJ 19,4

During the game, players actively strive to achieve their personal goals and strongly identify with negotiation contexts influenced by their actual relationships with their classmates. In a dynamic multi-round game, players improvise as they apply their knowledge and tactics for distributive bargaining, integrative bargaining, attitudinal structuring and intra-organizational bargaining, and practice their combined negotiation skills developed during the semester. The game is followed by a rich debrief where the instructor can review a wide scope of topics including all four negotiation subprocesses and students have opportunities to reflect on their negotiations and learn from their own and others' behaviors and tactics.

\section{Mechanics of the game}

The timeline of the game is provided in Table 1 . NegotioPoly can be used in any size class given each group has 4-6 players. A box of Monopoly MEGA edition is provided to each group. The instructor may ask the students to keep records during playtime using a tally sheet (see Appendix A for a sample).

\section{Topic coverage}

The following topics are covered by the game and can be chosen for the post-game debrief: Multi-round negotiations, multi-party negotiations, distributive and integrative negotiation strategies, attitudinal structuring, information exchange, power dynamics importance of trust and relationships and their impact on future negotiations, cooperative and competitive strategies and their impact on reputations and future negotiations, intra-organizational bargaining, multiple layers of interdependent negotiations, changing dynamics of coalitions and strategies to form and block coalitions. The versatility of the game to cover such a variety of topics in a class duration is an advantage of this game.

\section{Closing the gap between theory and pedagogy}

Coverage of attitudinal structuring. NegotioPoly provides naturally occurring multi-round negotiations among players in quick succession without the need to dedicate multiple class sessions. More specifically, during Negotipoly, players are constantly aware of the possibility of having to negotiate with the same people over and over again given the quickly changing dynamics on the game board. They are also constantly assessing other players in terms of their trustworthiness and competitiveness as they negotiate deals not only with themselves but also with others. Finally, most players start with negotiating smaller deals with other players to test out the trustworthiness of the other side and then move onto bigger deals with them as they build a relationship and mutually trust each other.

Coverage of intra-organizational bargaining. Negotipoly has multiple design characteristics that correspond to intraorganizational bargaining model. As partnerships and mergers start formulating, team-on-team negotiations foster multi-layered negotiations.

Table 1.

NegotioPoly game schedule
Sequence of activities

Time needed (minutes)

Participants' pregame preparation (to be completed outside of class)

Assigning participants to game boards, pregame instruction and reviewing rules

Game in action

Post negotiation survey (optional)

Debrief

Total class time:
10-20

10

55-90

5

45

110-150 min 
These new business relationships create intra-organizational dynamics for the teams as they negotiate among themselves before they move forward with any decision about new acquisitions or new negotiations with other players.

Debrief. After the game, the instructor can ask students to complete a post-game survey and capture the results regarding the total amount of money, properties and structures earned as well as number of negotiations, coalitions and partnerships to display during the debrief.

During the debrief, some of the following questions can be asked to students[1]:

Q1. How did you determine who to approach to negotiate?

Q2. What are some examples of negotiations you had?

Q3. How did previous negotiations with the same party influence the future rounds?

Q4. How did observing players negotiating with others influence your behaviors?

Q5. How did you choose who to partner with or create a coalition with?

Q6. Were there instances where initial coalitions/partnerships dissolve?

Q7. How did emotions influence your decisions during the game?

As part of these discussions, the instructor can review slides on distributive and integrative negotiations, multi-party and multi-round negotiations, reputations, trust, relationships, emotions, coalitions/partnerships and team negotiations. For enhanced focus on attitudinal structuring and intra-organizational bargaining processes, we suggest the following discussions:

Social dynamics involved in initiating a negotiation (re: attitudinal structuring). This discussion should include power dynamics, trust and relationship building. The natural follow up to this discussion is how an initial negotiation impacted follow up negotiations in the case of agreements versus impasses. The instructor can hold a discussion on the impact of impasses on not only future negotiations with the same individual but also with other players in the game. Additionally, the follow up discussion should include reaching an agreement that is perceived fair versus unfair and its impact on future negotiations with the same player and with other players. Here, a discussion can focus on the impact of observing other players negotiate, nicely tying into reputations and their impact on future negotiations.

Dynamics involved in coalition and partnership building (re: intra-organizational bargaining). As the game progresses and students start feeling financial strain, most will begin creating alliances. These alliances are rather fluid at the beginning, as players form multiple agreements with different players. As the game advances, these alliances solidify and turn into partnerships and sometimes mergers, which lead to intra-team negotiations when further opportunities arise for teams to work with the other players in the game. These discussions highlight the importance of intra-organizational bargaining, layered negotiations and the challenging act of balancing the needs and priorities of multiple parties.

Effectiveness of the game and sample student reactions. Throughout the five years we have been using it in undergraduate negotiation classes, NegotioPoly has been very well received by students. The overwhelming observation is that students have demonstrated high engagement with the exercise and held thoughtful and illuminating discussions during debriefs.

To assess the game's effectiveness, we conducted an exploratory study, where we collected post-game data from 66 students in three negotiation classes at an east coast 
OMJ 19,4

university business school (57.4\% female; $13 \%$ racial and ethnic minorities; mean age: 20, ranging between 19 and 24). Students played NegotioPoly following a 12-week course and then filled out a post-game survey, where we measured to what degree the core business competencies (i.e. working with others, decision-making, joint and creative problem solving), attitudinal structuring strategies and intra-organizational bargaining were practiced during the game (Likert scale: 5 = all the time, $1=$ never). In addition, we assessed the level of experiential learning on a variety of important negotiation topics such as interpersonal communication, creative deal making, power, reputations, rapport and relationships in negotiation, coalition and partnership formation and multi-party and multi-round negotiations. We also examined whether students were actively engaged throughout the game, whether they managed to reach deals and finalized transactions following their negotiations, and the degree to which they achieved their goals. Finally, we collected data on the number of negotiation attempts, number of players they negotiated with and number of partnerships they created.

Data showed that during the 60-min game, students frequently practiced core business competencies that employers are looking for during their hiring processes such as decisionmaking (mean: 3.64, sd: 1.18), working with others to obtain what one wants (mean: 3.94, sd: 0.82), joint problem solving (mean: $3.39, s d$ : 1.11) and applying creativity to reach agreements with others (mean: $3.70, s d$ : 0.94). These results show the high degree of demonstrated interpersonal communication, decision-making, problem solving and teamwork skills during the game.

Data indicated that, throughout the game, students very frequently engaged in negotiations with others (mean: 4.24, sd: 0.49), using their analytical skills to make calculations and device offers or proposals, communication skills to exchange information and convince others and distributive and integrative bargaining skills to reach agreements. One student commented that '[they] watched and listened to what other players were looking for and trying to accomplish and used it to [their own] advantage,' demonstrating student attempts to combine distributive and integrative bargaining tactics. Each game group witnessed multiple negotiations in every round, and all players closely observed each other's negotiations even when they did not personally take part in them. This transparent nature of the ongoing negotiations among different parties is a rare opportunity for all students to observe how real-life negotiators strive to make deals and address the priorities at multiple layers of interdependent parties. The reality that a series of internal (i.e. intraorganizational, intra-partnership, intra-coalition) negotiations impact the subsequent deals with external parties is clearly observable in NegotioPoly's unique environment.

At the individual level, students engaged in on average of 4 negotiations per game (min: 0, max: 15 , mean: $3.58, s d: 3.36$ ), and $89 \%$ of these negotiations resulted in an agreement/ transaction (min: 0, max: 12 , mean: $2.73, s d: 2.56$ ). In $76 \%$ of these transactions, students felt that they 'achieved their goal' (min: 0, max: 8, mean: 2.05, sd: 1.49). Both achievements and failures were discussed in the debrief, offering valuable learning opportunities. Furthermore, given that one traditional negotiation simulation takes one whole class time, achieving an average of 4 (and frequently higher; up to 15) realistic negotiations per student per class demonstrates both the efficacy of the game and the density of the student experience during the game.

Students also reported frequently observing the importance of social relationships and reputations (mean: 3.64, sd: 1.02), power differences (mean: 3.76, sd: 0.90) and emotions (mean: 3.12, sd: 1.33) in business transactions and their impact on negotiation behaviors and processes. These results show that, in NegotioPoly, students experienced the attitudinal structuring sub-process and practiced strategies to adjust their negotiation styles and 
methods to the specific contexts defined by the existing social relationships, individual reputations, emotions and power differences. Student comments highlighted adaptability and care about social and interpersonal contexts: "[I]f someone is too aggressive, you won't deal with them. If you're too soft, then someone will try to get more money from you;" "[The negotiators] adapted [their] style once [they] saw how others reacted to each other."

In response to more general survey questions about this educational experience, students reported that, during the game, they frequently practiced important skills that will be useful in the business world (mean: 3.94, sd: 0.70), and they frequently tried to identify their own strengths and used them to their advantage (mean: 3.91, sd: 0.76). As a further sign of high engagement, students reported (on a scale $5=$ very much and $1=$ not at all) that they enjoyed the game (mean: 4.39, sd: 0.65), and they highly recommended NegotioPoly for practicing decision-making (mean: 4.33, sd: 0.69) and negotiation skills (mean: 4.36, sd: 0.65). Some commented that "this game depends on more than just luck because the strength [and] quality of your negotiations can really help or hurt you." Some commented on each player's ability to make creative deals rather than being stuck on a negative outcome, stating that the most interesting aspect of the game was ' $h$ ]aving the ability to negotiate and create partnerships [...] [Y]ou have the ability to make a deal rather than just be out of money' which is a valuable practice of creativity skills students will benefit from in their careers.

Taken together, these findings demonstrate that NegotioPoly's speedy succession of multi-round and multi-party negotiations is fertile ground to experience and practice attitudinal structuring and intraorganizational bargaining sub-processes, in addition to distributive and integrative bargaining tactics. The game reinforces the theoretical concepts and negotiation skills covered throughout the semester, and students engage in improvisation and practice core business competencies, such as effective communication, decision-making, problem solving, teamwork and analytical skills. These improvisations signal increased transferability of the practiced skills to other contexts.

\section{Discussion}

NegotioPoly makes several valuable contributions to the negotiation and conflict management literature and pedagogy. First, NegotioPoly is an actual game versus a simulation, thus students do not assume roles but play as themselves. As a result, students are more personally engaged with the negotiations, and they strive to meet their true personal goals during the game. In addition to using both distributive and integrative negotiations, the current game incorporates realistic intra-organizational bargaining experiences. As students negotiate with different parties, they simultaneously resolve conflicts and create agreements within their coalitions and partnerships, giving them a realistic experience of layers of intra- and inter-organization interests that need to be negotiated and aligned. Unlike simulations where students read roles and their character's personal relationships, in this game, students have their own actual social and personal relationships with their classmates that developed over several weeks of class meetings in the semester. Therefore, in their negotiations, they experience the impact of their actual social perceptions and role conflicts, and they actively work to achieve their personal goals while trying to maintain positive future relationships. They do so, not as part of their role play, but as part of their social realities and real connections in the class. NegotioPoly also provides players with improvisation opportunities closely replicating real-life situations. During the game, students practice decision-making while other parties' actions and decisions constantly change. The flow of new information and fluid changes in coalitions push students into brand new negotiation contexts and dynamics that necessitate improvising and on-the-go decision-making. The game enables students to engage in multi- 
round negotiations in sequences, thus leading to a high number of negotiation experiences within a relatively short time. Players experience the impact of reputations, prior agreements and impasses on future negotiations with same and different negotiation partners first-hand. They engage in advanced deal-making behaviors such as forming coalitions and partnerships throughout the game, creating experiential learning opportunities for these high-level topics in a reasonable time frame. At the end of the class, the post-game debrief reveals high levels of reflection and conceptual learning.

Although we have used NegotioPoly successfully over the years, the game has certain limitations. For one, using the game necessitates some time investment for instructor learning and preparation. In addition, the game necessitates a minimum class time of $100 \mathrm{~min}$, and ideally $145 \mathrm{~min}$, which may be difficult to accommodate in some institutions. Also, on some occasions, the game can generate strong competitive urges among some students and can create emotional reactions although we believe that these are valid experiences that replicate real-life situations and offer students valuable growth opportunities.

More research is needed to investigate how experience of negotiation failures and harmful coalitions impact students' self-reflections and goal setting following the game. In addition, future research may assess the effectiveness and the flow of the game in different populations, such as more racially and ethnically diverse groups and in same versus mixed gender groups. Also the impact of different rewarding schemes (e.g. collecting class credit or assignment scores based on the outcomes) on student engagement and level of learning can be examined to identify the highest-impact version of the game.

Overall, NegotioPoly is an effective game-based learning activity that closes a gap between negotiation theory and pedagogy, reinforces a wide scope of negotiation topics and strategies and provides students with realistic opportunities to practice core business competencies and negotiation skills. Due to its unique context, improvisations and high student engagement, the transferability of the learning is high, preparing students for actual business contexts.

\section{Note}

1 Please contact the corresponding author to request sample answers from students and types of negotiations that can be observed during the game.

\section{References}

Abt, C.C. (1975). Serious games, New York, NY: Viking Compass.

Alexander, N. \& LeBaron, M. (2009). Death of the role-play. Rethinking negotiation teaching: Innovations for context and culture. Research Collection School Of Law. 179-197. Retrieved from https://ink.library.smu.edu.sg/sol_research/1872

André, R. \& Quinquis, G. (2000). Socofrance, SA: an American and French negotiation simulation. Journal of Management Education, 24(4), 501-519. doi: 10.1177/105256290002400408.

Breuer, J.S. \& Bente, G. (2010). Why so serious? On the relation of serious games and learning. Eludamos: Journal for Computer Game Culture, 4(1), 7-24.

Bochennek, K., Wittekindt, B., Zimmermann, S.Y., \& Klingebiel, T. (2007). More than mere games: a review of card and board games for medical education. Medical Teacher, 29(9-10), 941-948. doi: 10.1080/01421590701749813.

Burchill, F. (1999). Walton and McKersie, a behavioral theory of labor negotiations (1965). Historical Studies in Industrial Relations, 8(8), 137-168. doi: 10.3828/hsir.1999.8.7. 
Cutcher-Gershenfeld, J. \& Kochan, T.A. (2015). Book review: Editorial essay on the 50th anniversary of Richard E. Walton and Robert B. McKersie's a behavioral theory of labor negotiations. ILR Review, 68(4), 955-960.Available at: https://doi.org/10.1177/0019793915587284

Druckman, D. \& Ebner, N. (2013). Games, claims, and new frames: Rethinking the use of simulation in negotiation education. Negotiation Journal, 29(1), 61-92. doi: 10.1111/nejo.12005.

Ebner, N. \& Efron, Y. (2005). Using tomorrow's headlines for today's training: Creating pseudo-reality in conflict resolution simulation games. Negotiation Journal, 21(3), 377-394. doi: 10.1111/j.15719979.2005.00070.x.

Fortgang, R.S. (2000). Taking stock: an analysis of negotiation pedagogy across four professional fields. Negotiation Journal, 16(4), 325-338. doi: 10.1111/j.1571-9979.2000.tb00761.x.

Gray, K. (2021). The attributes employers seek on students' resumes. Retrieved from www.naceweb. org/talent-acquisition/candidate-selection/the-attributes-employers-seek-on-students-resumes/

Greenhalgh, L. \& Lewicki, R.J. (2015). Evolution of teaching negotiation: the legacy of Walton and McKersie. Negotiation Journal, 31(4), 465 doi: 10.1111/nejo.12130.

Jolin, D. (2016). The rise and rise of tabletop gaming. Retrieved from www.theguardian.com/ technology/2016/sep/25/board-games-back-tabletop-gaming-boom-pandemic-flash-point (accessed 24 July 2020)

Kochan, T. \& Lipsky, D.B. (2002/2018). Conceptual foundations: Walton and McKersie's subprocesses of negotiations. T. A. Kochan \& D. B. Lipsky, (Eds), Negotiations and change: from the workplace to society, (pp. 15-19) Ithaca, New York, NY: ILR Press.

Lewicki, R. (1997). Teaching negotiation and dispute resolution in colleges of business: The state of the practice. Negotiation Journal, 13(3), 253-269. doi: 10.1111/j.1571-9979.1997.tb00131.x.

Malhotra, D. \& Bazerman, M.H. (2008). Negotiation genius: How to overcome obstacles and achieve brilliant results at the bargaining table and beyond. Bantam.

Murnighan, J.K. (2002). A very extreme case of the dollar auction. Journal of Management Education, 26(1), 56-69. doi: 10.1177/105256290202600105.

Murnighan, J.K. (2015). Attitudinal structuring and game theory. Negotiation Journal, 31(4), 361 doi: 10.1111/nejo.12108.

Nohria, N. (2015). The legacy of great ideas: a tribute to Richard Walton and Robert McKersie. Negotiation Journal, 31(4), 501-503. doi: 10.1111/nejo.12133.

Papastergiou, M. (2009). Exploring the potential of computer and video games for health and physical education: a literature review. Computers \& Education, 53(3), 603-622. doi: 10.1016/j. compedu.2009.04.001.

Peart, N. (2019). The 12 most important skills you need to succeed at work. Forbes. Retrieved from www. forbes.com/sites/nataliapeart/2019/09/10/the-12-most-important-skills-you-need-to-succeed-at-work/ ?sh=40bf3e851c6a

Rabin, O. (2010). Mediation curriculum: Trends and variations. Teaching Negotiation, (3)2. Retrieved from http://archive.constantcontact.com//fs079/1101638633053/archive/1103432178067.html\#LETTER. BLOCK12

Randel, J.M., Morris, B.A., Wetzel, C.D., \& Whitehall, B.V. (1992). The effectiveness of games for educational purposes: a review of recent research. Simulation \& Gaming, 23(3), 261-276. doi: $10.1177 / 1046878192233001$.

Stokoe, E. (2011). Simulated interaction and communication skills training: the 'conversation-analytic role-play Method'. Applied conversation analysis, pp. 119-139. London: Palgrave Macmillan.

Taspinar, B., Schmidt, W., \& Schuhbauer, H. (2016). Gamification in education: A board game approach to knowledge acquisition. Procedia Computer Science, 99, 101-116. doi: 10.1016/j.procs.2016.09.104.

Thompson, L. \& Leonardelli, G.J. (2004). Why negotiation is the most popular business school course. Ivey Business Journal, 4, 1-7. 
Valdezco, C. (2021). Negotiation skills essentials 2021, London: Practising Law Institute.

Walton, R.E. \& McKersie, R.B. (1965). A behavioral theory of labor negotiations, New York, NY: McGraw-Hill.

Wong, J. (2017). How to design a business board game for employee engagement. Training Journal. Retrieved from www.trainingjournal.com/articles/features/how-design-business-board-gameemployee-engagement

\section{Further reading}

Greenblat, C.S. (1981). Gaming simulations for teaching and training: an overview. C. S. Greenblat \& R. D. Duke, (Eds) Principles and practices of gaming simulation, Beverly Hills, CA: SAGE. in

Kochan, T.A. (1992). Walton and McKersie's behavioral theory of labor negotiations: an industrial relations perspective. Journal of Organizational Behavior, 13(3), 289-295. doi: 10.1002/ job.4030130310.

Lewicki, R.J. (1981). Bargaining and negotiation. Exchange: The Organizational Behavior Teaching Journal, 6(2), 33-42.

McKersie, R.B. \& Walton, R.E. (2015). Reflections on negotiation theory, practice, and education: a robust record and new opportunities. Negotiation Journal, 31(4), 491-499. doi: 10.1111/ nejo.12132.

Pierfy, D.A. (1977). Comparative simulation game research, stumbling blocks, and stepping stones. Simulation \& Games, 8(2), 255-268. doi: 10.1177/003755007782006.

Raiffa, H. (1982). The art and science of negotiation, New York, NY: Harvard University Press.

Ratan, A. \& Ritterfeld, U. (2009). Classifying serious games. nU. Ritterfeld, M. Cody, \& P. Vorderer, Eds. Serious games: mechanisms and effects, pp. 10-24. New York, NY: Routledge. i

Walton, R.E. \& McKersie, R.B. (1992). Overview of a behavioral theory of labor negotiations. Journal of Organizational Behavior, 13(3), 275. doi: 10.1002/job.4030130308.

\section{Corresponding author}

Tuvana Rua can be contacted at: tuvana.rua@quinnipiac.edu

For instructions on how to order reprints of this article, please visit our website: 